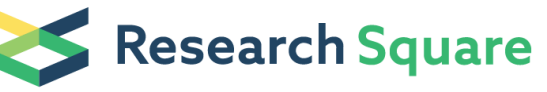 \\ Preprints are preliminary reports that have not undergone peer review. \\ They should not be considered conclusive, used to inform clinical practice, or referenced by the media as validated information.
}

\section{A case report of visual outcome in keratoconus with retinitis pigmentosa}

\section{Chiun-Ho Hou}

Department of Ophthalmology, LinKo Chang Gung Memorial Hospital; Chang Gung University College of Medicine, Taiwan

\section{Yun-Wen Chen}

Department of Ophthalmology, Kaohsiung Chang Gung Memorial Hospital; Chang Gung University College of Medicine, Taiwan https://orcid.org/0000-0002-5664-5655

\section{Ken-Kuo Lin}

Department of Ophthalmology, LinKo Chang Gung Memorial Hospital; Chang Gung University College of Medicine, Taiwan

\section{Jiahn-Shing Lee}

Department of Ophthalmology, LinKo Chang Gung Memorial Hospital; Chang Gung University College of Medicine, Taiwan

\section{Lai-Chu See}

Department of Public Health, College of Medicine, Chang Gung University, Taiwan and Biostatistics Core Laboratory, Molecular Medicine Research Center, Chang Gung University, Taiwan.

\section{Wan-Hua Cho}

Department of Ophthalmology, Kaohsiung Chang Gung Memorial Hospital; Chang Gung University College of Medicine, Taiwan

\section{Case Report}

\section{Keywords:}

Posted Date: November 1st, 2018

DOI: https://doi.org/10.21203/rs.1.6/v1

License: (c) (1) This work is licensed under a Creative Commons Attribution 4.0 International License. Read Full License 


\section{Abstract}

Background: It is uncommon to see retinitis pigmentosa in keratoconus patients. The main difficulty of visual rehabilitation for this is restricted visual field. We presented the treatment and gene screen of visual system homeobox 1 (VSX 1) gene in this case. Case presentation: A 24-year-old man with retinitis pigmentosa presented with progressively blurred vision. Slit lamp examination revealed Vogt's striae over both eyes, and corneal topography indicated bilateral keratoconus. We had tested 5 exons of VSX 1 gene from him and the did not find mutation on direct sequence. To improve visual acuity, we prescribed keratoconus rigid gas permeable (RGP) contact lens for him with good efficacy. However, lens dislocation occurred occasionally. He could not find dislocated lens easily due to visual field restriction, so he asked for more stable visual aids. Therefore, we instead prescribed scleral lens (SL), which were more stable on the ocular surface and led to more stable vision. Visual acuity was also gained with SL, but the tolerance time for SL was shorter compared to that of keratoconus RGP contact lens. To compare the efficacy of these two lenses, we surveyed life quality using the National Eye Institute Visual Functioning Questionnaire - 25 in three situations: baseline, with keratoconus RGP contact lens, and with SL. Conclusion: The patient used the two lens types according to his needs, and benefited from vision rehabilitation with both keratoconus RGP contact lens and SL. Keywords: keratoconus; retinitis pigmentosa; rigid gas permeable contact lenses; scleral lenses.

\section{Figures}




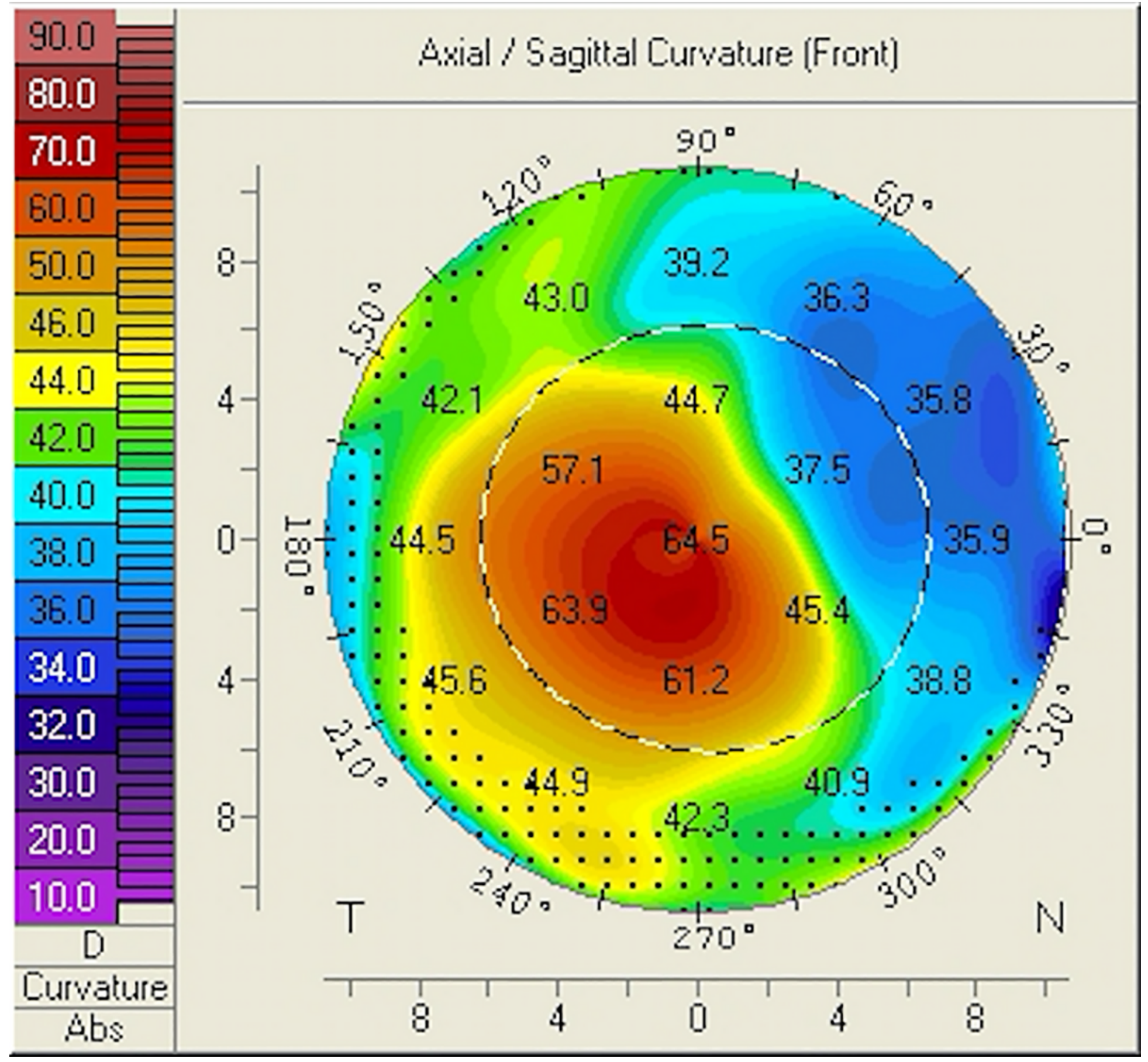

Figure 1

Topography of the right eye indicated keratoconus 


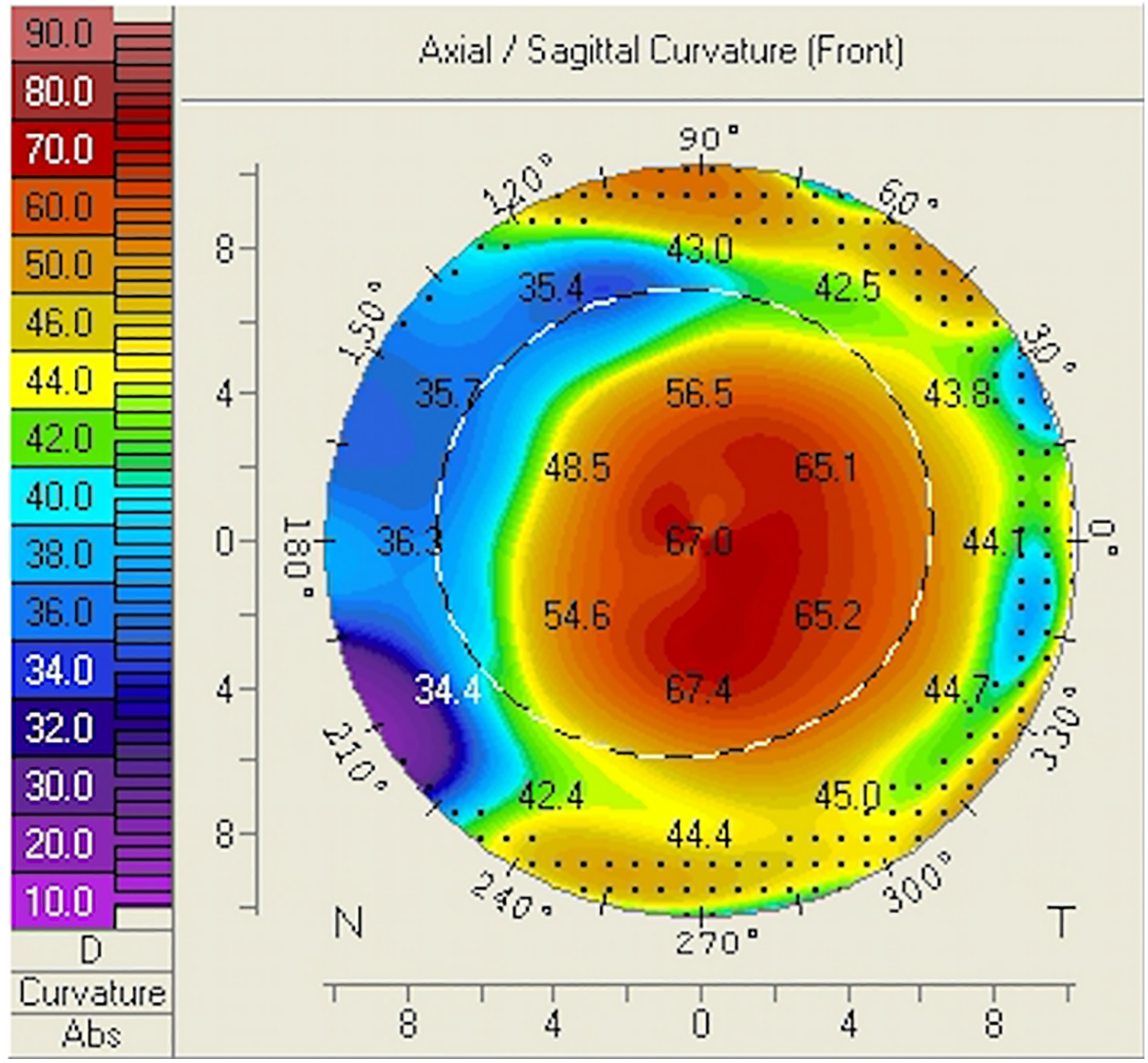

Figure 2

Topography of the left eye indicated keratoconus

\section{Supplementary Files}

This is a list of supplementary files associated with this preprint. Click to download.

- supplement0.docx 